\title{
Sepsis Causing Acquired Protein C and Protein S Deficiency
}

\author{
Arun Kannan, ' Swetha Chandra,' Jose Lizcano,' Christie Murphy \\ 'Canton Medical Education Foundation, Canton OH, USA.
}

\section{ABSTRACT}

Warfarin Induced Skin Necrosis is a well-known and dreaded complication in patients who is being started on warfarin without adequate bridging with other anticoagulants. The mechanism is thought to be due to protein $C$ deficiency acquired after initial exposure to warfarin. We present a rather unusual cause of protein $\mathrm{C}$ deficiency due to sepsis resulting in warfarin induced skin necrosis. 43 year old lady who has been on chronic warfarin therapy secondary to anti phospholipid syndrome was admitted to the hospital for acute ischemic cerebellar stroke. Warfarin was held due to acute thrombocytopenia. She was discharged after restarting the warfarin. She presented back with septic shock due to pneumonia. She was found to have multiple necrotic areas consistent with skin necrosis. Unfortunately, patient died due to multi organ failure despite goal directed therapy. This case demonstrates the importance of recognizing the sepsis as an acquired cause of protein C deficiency.

Keywords: protein C; Protein S; sepsis; skin necrosis; warfarin.

\section{INTRODUCTION}

Warfarin-induced skin necrosis is rare with prevalence of $0.01-0.1 \%$ of warfarin treated patients but potentially life threatening complication of anticoagulant therapy with an associated morbidity and mortality requiring immediate drug cessation. ${ }^{1}$ We present a rather unusual cause of protein $\mathrm{C}$ deficiency due to sepsis resulting in warfarin induced skin necrosis. This article explains the importance of sepsis as a cause of acquired Protein C and protein $\mathrm{S}$ deficiency. We believe that sepsis is a very common condition and associated complications should be identified.

\section{CASE REPORT}

Our patient is a 43 year old Caucasian female with a history of anti phospholipid syndrome (APLS) complicated by multiple deep venous thrombosis (DVT) and pulmonary embolism (PE) on warfarin therapy for 10 years. Patient had a recent hospitalization for ischemic cerebellar stroke, She developed acute thrombocytopenia during that admission and warfarin was discontinued. On discharge warfarin was restarted on the same dose $(7.5 \mathrm{mg})$ and transferred to the nursing home. About 10 days later patient was readmitted with fever and hypotension. She was diagnosed with septic shock secondary to pneumonia and admitted to the Intensive Care Unit. Physical exam revealed black eschar lesions in the left inframammary and right groin region (Figure 1). The lesions started to appear 5-6 days after restarting Warfarin. It started as an erythematous lesion and within 48 hours had progressed to painful black eschars. The inframammary lesion was $6 \mathrm{~cm}$ by $15 \mathrm{~cm}$ and the left groin lesion measured $7 \mathrm{~cm}$ by $12 \mathrm{~cm}$. A clinical diagnosis of warfarin induced skin necrosis was made. Warfarin was discontinued and therapy with UFH was initiated intravenously. Biopsy of the lesion in the groin was performed and it revealed superficial

Correspondence: Dr. Arun Kannan, Canton Medical Education Foundation, 2600 Sixth St SW, Canton OH, USA. Email: arsk83@gmail. com, Phone: +13304121641 . 
dermal fibrin thrombi, hemorrhage and ischemic changes (Figure 2). These findings were consistent with Warfarin Induced Skin Necrosis (WISN). Unfortunately despite goal directed therapy the patient died due to multi-organ failure.

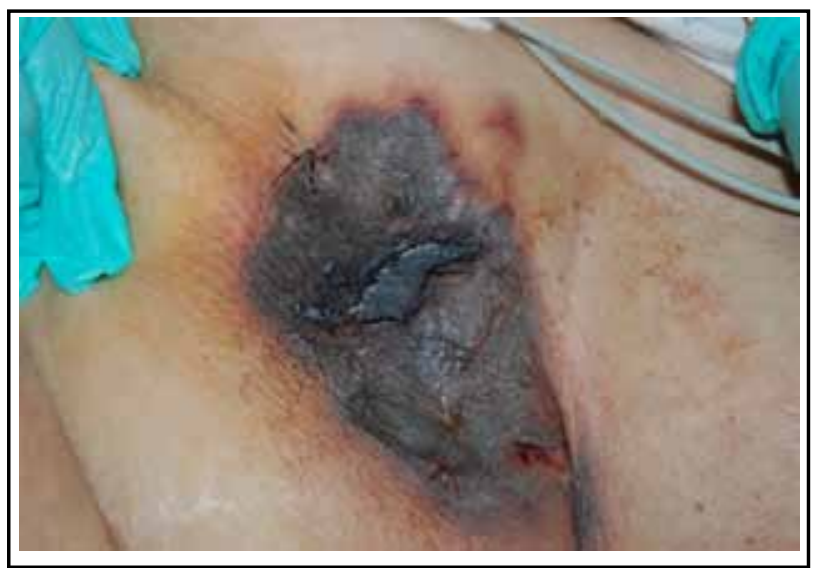

Figure 1. Showing warfarin induced skin necrosis under the left infra mammary region

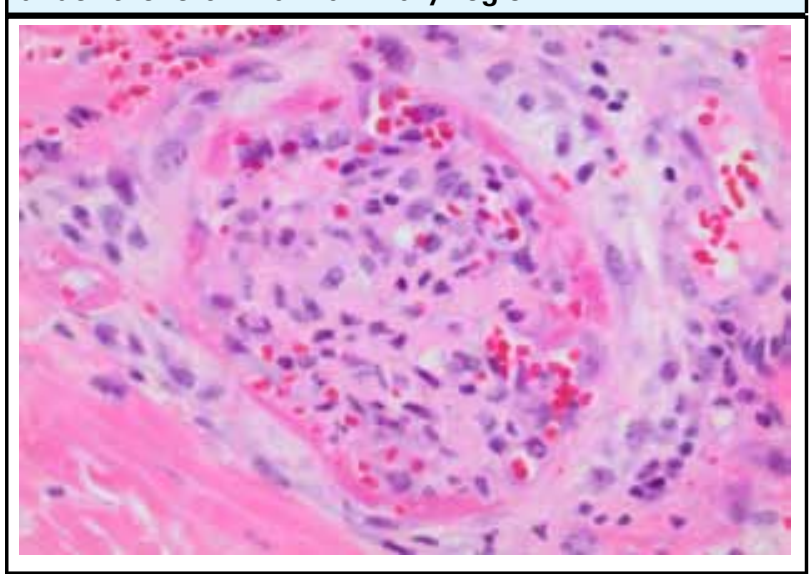

Figure 2. Showing Histopathological image of the skin necrosis showing superficial dermal fibrin thrombi, hemorrhage and ischemic changes consistent with warfarin induced skin necrosis

\section{DISCUSSION}

Approximately 300 cases of (WISN) have been reported in literature. The earliest symptoms of WISN appeared within 10 days of restarting warfarin with the peak incidence between days 3 and 6 (83-90\% of cases). ${ }^{2,3}$
WISN is a potentially catastrophic complication of warfarin therapy that arises as a consequence of different half-lives of the vitamin $\mathrm{K}$ dependent proteins. After the first day of initiating the usual doses of warfarin, the level of protein C decreases by $50 \%$ (same as factor VII). Rest of the vitamin $\mathrm{K}$ dependent clotting factors have half lives of 48-60 hours and their levels decline more slowly in the serum leading to a transient imbalance procoagulant-anticoagulant proteins. Such an imbalance occurs during the initial phase of anticoagulation therapy, which creates a hypercoagulable state. This leads to thrombotic occlusions of the microvasculature causing necrosis as seen in our patient. The effect is more pronounced when a higher dose of warfarin is administered.

The most common cause has been attributed to hereditary protein $C$ deficiency. ${ }^{4-6}$ Other conditions causing WISN are acquired causes of protein $\mathrm{C}$ deficiency like acute thrombosis, warfarin therapy, vitamin $\mathrm{K}$ deficiency, ${ }^{6}$ liver disease, DIC, chemotherapeutic agents for breast cancer, ${ }^{7,8}$ sepsis, ${ }^{9,10}$ primary antiphospholipid syndrome, ${ }^{11}$ acute exacerbation of ulcerative colitis, ${ }^{12}$ protein $\mathrm{C}$ auto-antibody formation. ${ }^{13}$

In our patient, the appearance of WISN lesions that appeared on the $6^{\text {th }}$ day of reintroduction of warfarin therapy is most likely due to have multiple factors. Septic shock, which is known to be one of the causes of transient acquired protein $C$ deficiency, could have contributed to the WISN lesions in addition to the recent reintroduction of warfarin in our patient. Since the patient was initiated on heparin therapy the levels of protein $\mathrm{C}$ and $\mathrm{S}$ could not be assessed. Patient was also treated with broad-spectrum antibiotics on admission, which could have further contributed to the acquired protein $\mathrm{C}$ deficiency by reducing gut flora, intestinal malabsorption and thus reducing vitamin $\mathrm{K}$ levels.

There are only two cases of acquired protein $C$ deficiency reported in literature. ${ }^{14,15}$ One of these patients had similar catastrophic outcome as our patient- Death from multiorgan failure. This case demonstrates the importance of prompt recognition of acquired causes of protein $\mathrm{C}$ and $\mathrm{S}$ and avoidance of skin necrosis in this scenario.

\section{REFERENCES}

1. Chan YC1, Valenti D, Mansfield AO, Stansby G. Warfarin induced skin necrosis. Br J Surg. 2000 Mar;87(3):266-72.

2. Nalbandian R, Mader I, Barrett J, Pearce J, Rupp E: Petechiae, eccymoses and necrosis of skin induced by coumarin congeners. JAMA. 1965;192:107-12.
3. Horn J, Danziger L, David R: Warfarin -induced skin necrosis: Report of four cases, Am J Hosp Pharm. 1981;38:1763-8.

4. McGehee WG, Klotz TA, Epstein DJ, Rapaport SI. Coumarin necrosis associated with hereditary protein deficiency. Ann Intern Med. 1984;100:59-60. 
5. Rose VL, Kwaan HC, Williamson K, Hoppensteadt D, Walenga J, Fareed J. Protein C antigen deficiency and warfarin necrosis. Am J Clin Pathol. 1986;86:653-5.

6. Presgrave P, Ma D. Genetic predisposition to venous thromboembolism: moleculer basis and a practical guide to management. Aust NZ J Phleb. 2000;4:39-45.

7. Taher A, Shamsseddine A, Saghir N, Seoud M, Mourad F, Dabajah B, Khlil A. Acquired protein C deficiency following cisplatinum-nevelbine administration for locally advanced breast cancer. Eur J Gynaecol Oncol. 1999;20:325-4.

8. Feffer SE, Carmosino LS, Fox RL. Acquired protein $\mathrm{C}$ deficiency in patients with breast cancer receiving cyclophosphamide, methotrexate, and 5-fluorouracil. Cancer. 1989;63:1303-7.

9. Fisher JJ, Yan SB. Protein C levels as a prognostic indicator of outcome in sepsis and related diseases. Crit Care Med. 2000;28:49-56.

10. YanSB, Helterbrand JD. Low levels of protein C are associated with poor outcome in severe sepsis. Chest. 2001;120:915-22.
11. Ruiz-Arguelles GJ, Ruiz-Arguelles A, Deleze M, Alarcon-Segovia D. Acquired protein C deficiency in a patient with primary antiphospholipid syndrome. Relationship to reactivity of anticardiolipin antibody with thrombomodulin. J Rheumatol. 1989;16:381-5.

12. Korsten S, Reis HE. [Acquired protein C deficiency in ulcerative colitis. The cause of thromboembolic complications]. [Article in German]. Dtsch Med Wochenschr. 1992 Mar 13;117(11):419-24.

13. Mitchell CA, Rowell JA, Hau L, Young JP, Salem HH. A fatal thrombotic disorder associated with an acquired inhibitor of protein C. N Engl J Med. Dec 24 1987;317(26):1638-42.

14. Argaud L, Guerin C, Thomas L, Fournier G. Extensive coumarin -induced skin necrosis in a patient with acquired protein C deficiency. Intensive Care Med. 2001;27:1555.

15. Parsi K, Younger I, Gallo J. Warfarin-induced skin necrosis associated with acquired protein $\mathrm{C}$ deficiency. Australas J Dermatol. 2003 Feb;44(1):57-61. 